\title{
Views and (Re)Views Notes on how to win (the L'Atelier) and still be free
}

\author{
Pieter Swanepoe/*
}

\section{* Pieter Swanepoel is a lecturer in the Department of Visual Arts at the University of Pretoria.}

Perhaps we have become comfortably numb ever since Barthes' (1977:146) distressing yet emancipating signal that all texts function on multidimensional levels at once, to disclose divergent and clashing opinions rather than a singular foregone conclusion professed by a godly author. Still, one would think that competitions (particularly as texts indicative of an apogee) would, within a traditional understanding of what the word 'competition' stands for, remain an exception to the rule. Do we not still find it hard to shake the (di)vision of dark clouds gathering, brought on by the mere idea of a competition; and however exciting such a gathering storm might at first appear, is the butting of heads not true to the nature of competitions; are acrid arguments not flung far and wide within this arena of dramatic conflict? And in the end, after all the struggle and strife, once the violent attacks and total onslaughts have ceased, when all thumbs of all in the audience - including the Caesar - have doomed all losers through vigorous downward gesticulations, yea, after the dust has finally settled, one heroic winner remains standing .... To talk of balance, then, from within such an understanding would seem like the epitome of hypocrisy and contradiction. And yet ... contradiction and paradox might just be the binding agents needed to identify harmony within a framework otherwise exemplified by dissonance.

This year the curatorial theme for the Absa L'Atelier, silver foiled in curly cursive text, consisted of three capitalised words: Creativity Takes Courage. Which might prompt the question: does courage mean winning in the face of competition? Or should the competitor have courage to break free from such nagging suspicions; perhaps even, would it be possible to be free within the confines of an institution so prominent for its contradictions?

Over and above such lofty thoughts as courage and freedom within contradiction, we would do well to bear in mind that a certain aspiration towards balance (would it be between freedom and limitation?) remains an old ideal within the arts: hence we are reminded that in antiquity, the classical Greeks aimed at harmonising the polar oppositions of body and soul. And while this ideal was revived during the Italian Renaissance, the added premise of creative thinking, i.e. renewal, was propagated by Vasari, most notorious for being the founding father of theory of art. But there is the added understanding that such creative endeavours play out against a backdrop of tradition, and however much modernist avantgarde practices liked to proclaim the demise of such traditions, old habits remained in place for the establishment of a Western canon. Hence even Greenberg (Harrison and Wood 1996:760) would insist that Modernism was not a 'rupture of continuity' in terms of the past, but rather a penetrating investigation of the preceding traditions of art. In turn, Kuspit (1993:54) chooses to refer to the 'modern traditionalist artist' whom he believes walks a tightrope through testing the strengths and weaknesses of modernism. The modern traditionalist is someone who negates rather than affirms tradition as such. One way of doing this would be to employ the identity of tradition through the use of quotations.

Seen in this light, it might seem as if the Absa L'Atelier competition has, until now, functioned in a rather modern traditionalist mode: existing norms and boundaries are tested and even negated, without radical wholesale rejection. In a way a lot of what has appeared within this competition (ever since its inception 25 years ago) could still be understood according to Baudrillard's (1983) constitution of the concept of simulacra, with its emphasis on repetition and its denial of any originality whatsoever. We are hence confronted by a competition that is not formless at all. On the contrary, its form can be seen to be determined by the very tradition within which it functions. And one of these form-giving elements clearly remains the need for dynamic shifts within the form itself. Accordingly, the competition's own tradition could be described as re-productive rather than productive. Even the winning work of this year's competition can be examined according to this legend.

No process of reading ever takes place against a blank backdrop; any search for understanding would, according to hermeneutics, be established by a-priori information, of existing horizons which give rise to prejudice (Gadamer 1986), according to which a text will then be read. In this sense, no reading of any text can ever be said to be an original reading; rather, it is always a rereading. Moreover: that each reading hereafter 
will enter deeper into the text in its search for better insight.

Allow me a short ekphrasic pause in order to note, rather than determine, a possible outlay of this year's winning work - Ilka van Schalkwyk's Reading Colour (2009), which clearly calls attention to a re-reading: on one level it is perhaps most obvious in its referencing of synesthesia, while at the same time it clearly points towards the work being a translation. The artist did, after all, make an artwork from translating an existing book. But instead of translating the words from one written language to another, she transcribed it from one medium to another. In this instance the letters of the words are converted to colours, which is plainly what happens in some cases of synesthesia. As visitor to this year's Absa L'Atelier we are invited to not only literally read Van Schalkwyk's translation of Rushdie's book, Haroun and the sea of stories, but to also take note of and perhaps even read the book as metaphorical of the creative process of art making. The question that arises now is how we read and hence interpret Van Schalkwyk's reading of Rushdie's book, as filtered or mediated through or even contaminated by synesthesia.
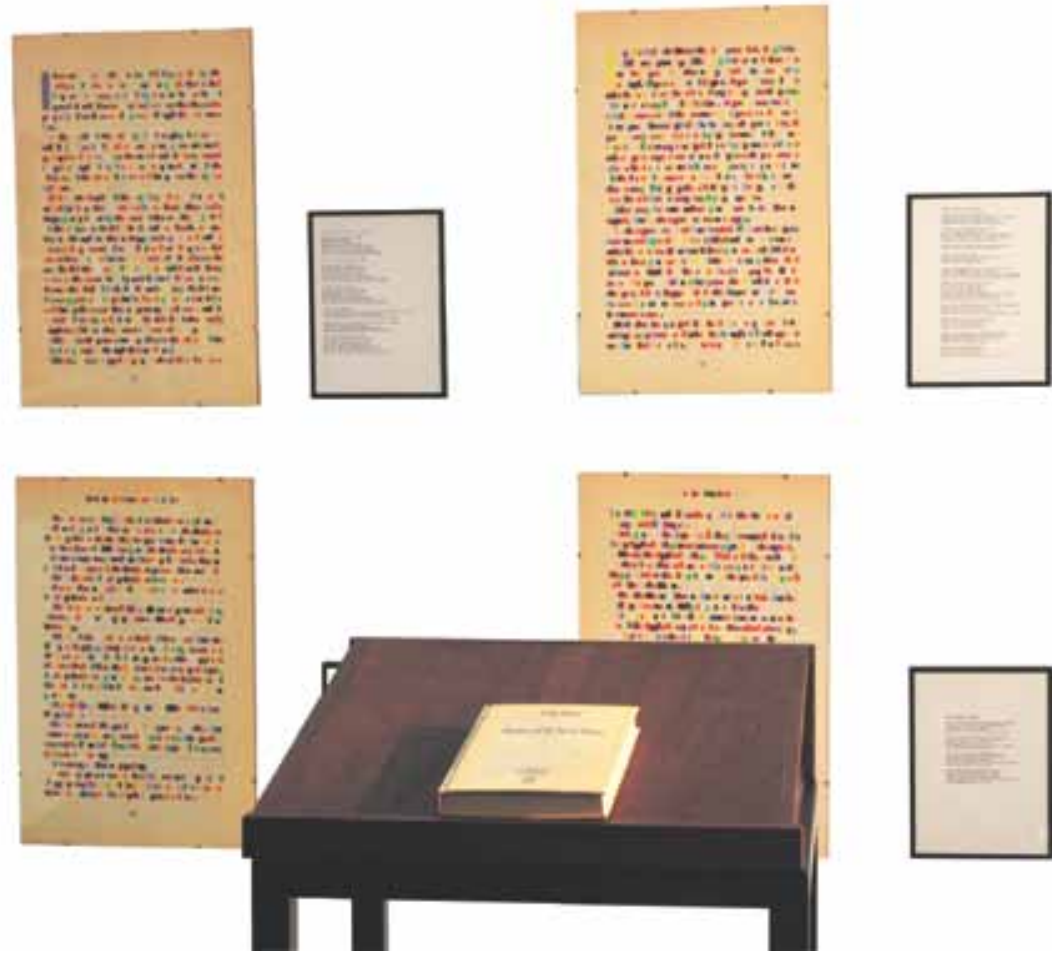
with the simulated book made up of pages of small colour patches literally determined by the Rushdie text are a number of enlarged pages extracted from the book, as well as a handful of protest texts of varying disposition. It seems as if the main purpose of the enlarged facsimiles extracted from the book would be for visual enticement - simply to draw the viewer's attention to the content of the book. The other inter-disposed texts, however, clearly serve as a key to the translation or re-reading of Rushdie's book. It asks of the viewer to investigate and apply the codification of colours that replaced certain letters. Only through reading all the 'protest texts', and thus gathering the transcribed letters, can the complete alphabet be gathered. These supplementary texts thus serve as a Rosetta stone according to which the book on the podium can be read back, or in a sense even be read backwards. In this way the viewer is compelled to share the world of someone who suffers from synesthesia, while experiencing how the making of such a work could serve as a catalyst for overcoming what is believed to be an affliction. We may come 
to realise, also, that despite its title, what we are doing is not to read colour, nor are we reading by means of colour. We rather share an experience: this is how it is to read when colours appear in the place of letters, when the normative tradition of reading is shifted from one format to another. And the question we may come away with is this: How does such a re-reading impact on our understanding of the reading of the text?

We may also find that these shifts could move our attention to our canonical thoughts on art competitions, and then how the Absa L'Atelier, as the longest-surviving art competition in South Africa, may have experienced and weathered the many shifts and changes it has endured over the years. Cecile Loedolff (2010), curator of Absa's visual arts, explains in an interview - eked on by my own curiosities and prejudices - that there are two elements to the Absa L'Atelier that might constitute a tradition: that young, lesser-known artists are afforded an opportunity of exposure, but that such artists at the same time should show a true willingness to shift boundaries. According to Loedolff, the competition itself survived in a similar manner - through constantly making the necessary shifts in as creative a manner as possible. She agrees that there are any number of limitations at any given time, which she believes is not only part of any competition, but part of life in general - limitations concerning practicalities like space, place, costs and the like. Thus, for example, it was decided some years ago that performance pieces would no longer be part of the competition. Excluding performances was prompted, firstly, by insurance difficulties and also by practical considerations, such as the availability of the artist as the competition stipulates that any work entered should be available for the duration of the exhibition one could hardly expect of a performance artist to sit around in the gallery all day, waiting for an audience to arrive in order to give a performance. A way around this would be to enter a video of a particular performance. Loedolff is, moreover, of the opinion that distinctive limitations within the competition should not be seen as stumbling blocks, but rather as encouragement for creative and innovative thinking. She insists: 'It is only by being able to overcome such limitations while working within the narrow boundaries of an institution that the artist will be truly free.' This reminds me of Lyotard's (quoted in Sarup 1988:120) assumption concerning Wittgenstein's comments on language games: 'The war is not without rules, but the rules allow and encourage the greatest possible flexibility of utterance.'

Other changes include the fact that what was initiated as the Volkskas Atelier 25 years ago by Roena Griesel (the then chair of the South African Arts Association) changed according to the status and amalgamations of the financial institution concerned, with its funding as well as the fact that the Absa L'Atelier exhibition was moved from pillar to post, until it eventually found a home in the current Absa Gallery in downtown Johannesburg, from where it still sends the work of its top ten artists to Potchefstroom's Aardklop arts festival for greater exposure.

The exhibition catalogue has also undergone major changes over the years, in order for it to appear in its current professional format. Over and above the images of artworks on exhibition, the catalogue now also includes artists' statements - an internationally accepted standard, without which it might have been difficult to make much of this year's winning work. But despite considerations of artistic intent by means of the artist's statement, the viewer's engagement with the work remains paramount. What is more, the engagement of the viewer remains a matter of personal predilection and understanding. Consider the view of Beeld newspaper's art critic, Johan Myburg (2010), that the winning work is 'singularly cerebral', against the possibility that the work came into being in a rather intuitive manner and that is should hence be interpreted accordingly - particularly in light of MaholyNagy's (1947:68) assertion that it remains almost impossible to verbalise the intuitive, and that intuition could best be expressed through a variety of senses in the arts. This would explain why someone who suffers from synesthesia would, almost in an instinctive or intuitive manner, want to express her experiences in an alternative visual format. And even if one would agree with Myburg on the work being cerebral, perhaps then its very own internal logic should be considered as a form of intentionality. It is, moreover, through exposing the process of the making in the work itself that Van Schalkwyk sets up another clue: the numbingly repetitive process of literally overlaying each and every letter in Rushdie's book with a corresponding 
colour (as experienced purely subjectively by the artist) can furthermore be understood in light of Foucault's (Norris 1991:87) argument that repetition causes the demise of existing systems that rely on 'a logic of noncontradiction'.

The shift from one to the other now appears effortly seamless: that which only for a moment appeared as the other has now become the same - the text the colour - so that we (barely) take any notice. Derrida would very easily have seen Van Schalkwyk's shifts as contaminations, as 'a sort of participation without belonging' (in Foster 1985:90). From this we could now also realise how much freedom the competition allows the artist: the individual artist's articulation with a broader (art) public could be seen to reside in the artist's intervention between personal freedom and institutional design. Even if this means that the artist participates without ever belonging.

\section{References}

Barthes, R. 1977. Image, music, text. Trans. S. Heath. Glasgow: Fontana/Collins.

Baudrillard, J. 1983. Simulations. New York: Semiot(e)xte.

Foster, H, ed. 1985. Postmodern culture. London: Pluto Press.

Gadamer, H. 1986. Truth and method. New York: Crossroad.

Harrison, C. and P. Wood, eds. 1996. Art in theory: 1900-1990: An anthology of changing ideas. Oxford, UK and Cambridge, USA: Blackwell.

Ludolff, C. 2010. Interview at the Absa Gallery, Johannesburg, 29 August.

Maholy-Nagy, L. 1947. The new vision and abstract of an artist. New York: George Wittenborn.

Myburg, J. 2010. Telephonic conversation with Johan Myburgh, from Pretoria, 22 July.

Norris, C. 1991. Deconstruction: Theory and practice. London and New York: Routledge.

Sarup, M. 1988. An introductory guide to poststructuralism and postmodernism. New York and London: Harvester Wheatsheaf. 